\title{
LABELISASI HALAL DAN HARAM
}

\author{
Desy Kristiane \\ Fakultas Syariah IAIN Palu \\ Email: desy_kristiane@iainpalu.ac.id
}

\begin{abstract}
Halal certification within the scope of modern society as it is today raises a bit of concern for some products that do not have a halal certificate. When reviewed in figh books, we will find al-tahrim wal ihlâl haqqullâh wahdah. This is studied descriptively and qualitatively. There are three problems related to the issue of halal labeling which so far the rights are in the hands of the MUI. First, is the political problem caused by labeling itself. Second, is a religious issue. Third, related to economic matters.
\end{abstract}

Keywords: Halal Label; Halal and Haram; Halal Certificate.

\begin{abstract}
Abstrak
Sertifikasi halal didalam lingkup masyarakat modern seperti sekarang ini menimbulkan sedikit kerisauan terhadap sejumlah produk yang tidak memiliki sertifikat halal. Apabila ditinjau dalam pustaka pustaka kitab fiqih, kita akan menemukan al-tahrîm wal ihlâl haqqullâh wahdah. Ini dikaji secara deskriptif dan bersifat kualitatif. Ada tiga masalah yang berkaitan dengan persoalan labelisasi halal yang dalam ini wilayah haknya ada di tangan MUI. Pertama, adalah masalah politis yang ditimbulkan soal labelisasi itu sendiri. Kedua, adalah masalah keagamaan. Ketiga, menyangkut soal ekonomi.
\end{abstract}

Kata Kunci: Labelisasi; Halal dan Haram; Sertifikat Halal.

\section{A. PENDAHULUAN}

Agama Islam adalah agama yang kompleks dan ajarannya pun saling berkesinambungan, dimana beberapa masalah hukum satu sama lain saling berhubungan. Dalam mengatur masalah ibadah pun tak luput di dalamnya terkait masalah yang lainnnya termasuk dampak halal dan haramya suatu makanan dan minuman.

TADAYUN: 
Islam mengajarkan sikap wara', yaitu sikap seorang muslim yang hendaknya menghindari segala sesuatu yang syubhat ${ }^{1}$ agar tidak terjerumus pada hal-hal yang haram. Implikasi dari keduanya akan bertumpu pada diterima tidaknya ibadah kita. Seorang yang terbiasa memakan harta yang halal akan memancarkan cahaya keimanan dalam hati, menambah kekhusyuan dalam beribadah dan mengurangi kecenderungan pada dunia. Dengan demikian akan diterimalah amal ibadah dan doa-doa kita.

Pada dasarnya Allah menciptakan segala sesuatu di muka bumi ini hukumnya adalah mubah, tidak ada sesuatu yang haram kecuali adanya nash yang sah dan tegas dari syar'i yang mengharamkannya. Namun hukum mubah ini kemudian berkembang, dapat menjadi halal, haram, syubhat, makruh dan atau tetap mubah apabila tidak ada atau nas yang menjelaskannya lemah.

Terhadap makanan, orang hanya cenderung memperhatikan rasanya atau tern-nya saja. Padahal unsur halal-haramnya lah yang seharusnya diperhatikan. Makanan yang suplai ke dalam tubuh, akan berpengaruh pada perkembangan fisik maupun psikis manusia. Makanan yang halal tidaklah sebatas yang enak dan higienis saja, namun harus pula diperhatikan gizi dan esensinya baik untuk jasmani maupun rohani.

Pada zaman sekarang ini, sangat sulit dibedakan antara makanan yang halal dan makanan yang haram. Secara kita sebagai konsumen sangat bergantung pada produk-produk yang dikemas dalam bentuk yang sedemikian rupa. Terkadang, kita hanya memperhatikan unsur higenisnya saja dengan dalih, tidak mengandung racun dan dapat dimakan. Orang baru menyadari manakala secara empirik menemuksn ekses negatif baik secara jasmaniah maupun rohani.

Permasalahannya sekarang adalah, bagaimanakah cara mengidentifikasi mana makanan yang halal dan haram yang pada kenyataanya, tetap saja masih ada kasus yang timbul terkait permasahan ini. seperti kasus minyak babi dalam penyedap rasa ajinomoto, yang terjadi beberapa tahun silam dan baru-baru ini

\footnotetext{
${ }^{1}$ Yusuf Qardhawi, Halal Haram Dalam Islam, trans. Wahid Ahmadi, M Badawi, and Saptorini (Solo: Era Intermedia, 2007), 61.
} 
merebaknya pemberitaan tentang adanya unsur melamin pada beberapa makanan ringan, seperti oreo dan sejenisnya, meskipun di dalam produk-produk makanan terdapat label halal. Bukankah permasalahan labelisasi tersebut tersebut tak lepas dari kiprah fatwa MUI dan LP-POM sebagai lembaga yang berperan untuk menangani masalah perlindungan konsumen.

\section{B. PEMBAHASAN}

\section{Pengertian Halal dan Haram}

Kata halal atau halla merupakan asal kata dari bahasa Arab yang memiliki arti tidak terikat atau lepas. Pada kamus fikih, halal diartikan dan dipahami sebagai sesuatu yang boleh untuk dilakukan atau dimakan. Istilah halal digunakan pada umumnya berkaitan dengan masalah makanan dan minuman.

Kata haram merupakan lawan kata dari halal. Kata ini juga berasal dari bahasa Arab yang memiliki makna, suatu perkara yang terlarang oleh syara (agama). Mengerjakannya akan mendapatkan dosa dan akan mendapat pahala bila meninggalkannya. Misalnya, memakan darah, bangkai hewan, minum khamr, memakan barang yang didapatkan dari mencuri.

Mengetahui mana yang hukumnya halal dan mana yang hukumnya haram hukumnya wajib karena termasuk yang sangat dianjurkan didalam agama, ini sangat erat hubungannya dengan siksa yang sangat pedih bagi orang yang memakan makanan atau minuman yang haram. ${ }^{2}$

\section{Kriteria Halal dan Haram.}

Islam memberikan batasan untuk menentukan halal dan haram, yaitu dengan melepaskan hak-hak tersebut dari manusia, tidak peduli seberapa tinggi status manusia dalam ranah agama dan sekuler. Hak ini hanya milik Allah swt..

a. Kriteria Makanan dan Minuman yang Halal

\footnotetext{
${ }^{2}$ Muhammad Arsyad Al-Banjari, "Kitab Sabilal Muhtadin," in Juz II (Surabaya: Bina Ilmu, 2002), 497.
} 
Mengenai otoritas kehalalan suatu makanan, dalam al-Qur'an hanya disebutkan adanya perintah untuk makan makanan yang halal dan baik. Sebagaimana yang dijelaskan dalam Q.S. al- Baqarah [2]: 168

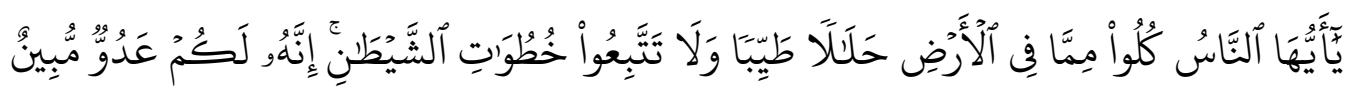

Terjemahannya:

'Wahai sekalian manusia makanlah sebagian dari makanan yang ada di bumi ini yang halal dan yang baik dan janganlah kamu mengikuti langkah-langkah syeitan. Sesungguhnya setan adalah musuh yang nyata bagimu.'

Al-Qur'an tidak secara jelas mengklasifikasikan mana saja yang disebut halal. Justru yang banyak disebutkan adalah tentang jenis-jenis makanan yang tergolong haram. Seperti yang tertuang dalam sural al-Maidah: dari sini para fuqaha' berkesimpulan bahwa makanan yang halal yaitu makanan selain yang disebutkan dalam nash.

Dari ketiadannya pernyataan halal pada sesuatu yang dijelaskan hukumnya dalam al-qu'an maupun hadis atau memanng secara teknis praktis tidak diatur, maka hal ini masuk dalam wilayah ijtihadiyah. Dan disinilah peran fuqaha untuk berijtihad. Hal ini berdasarkan keputusan fikih dalam serangkaian pembahasan hukum islam terhadap pendapat yang berkembamg. Maka dari itu para fuqoha memberikan kriteria halal dan haramnya sesuatu, dan dalam masalah ini adlah makanan ataupun minuman

Kriteria halal menurut para fuqaha' di atas terbagi menjadi dua ${ }^{3}$, yaitu :

1) Makanan halal dalam mendapatkannya

Al-qur'an menjelaskannya dalam dua ungkapan, kalau dilihat dari lawan katanya. Yang pertama halal sebagai lawan haram, dan yang kedua, dengan lawan kata batil. Halal dengan lawan kata haram sebagimana disebutkan dalam Q.S. Al Baqarah [2] : 275

${ }^{3}$ Thobieb al-Asyhar, Bahaya Makanan Haram (al-Mawardi Prima:2003)cet I hal 98 


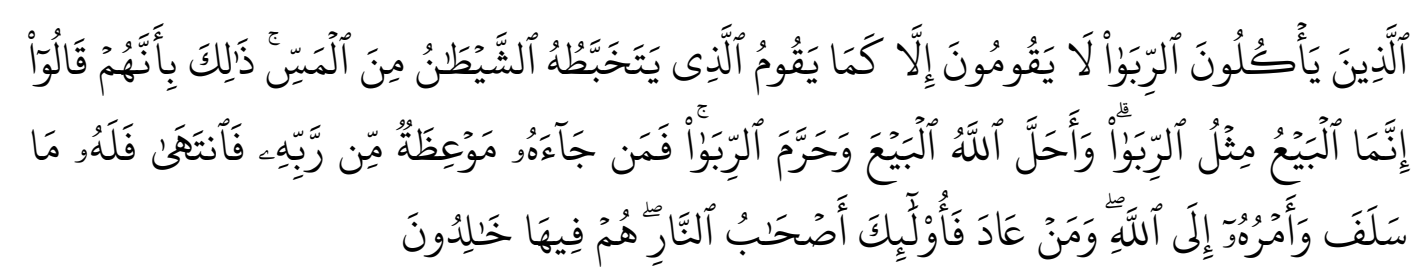

Terjemahannya:

'Orang-orang yang memakan riba tidak dapat berdiri melainkan seperti berdirinya orang yang kemasukan setan karena gila. Yang demikian itu karena mereka berkata bahwa jual beli sama dengan riba. Padahal Allah telah menghalalkan jual beli dan mengharamkan riba. Barangsiapa mendapat peringatan dari Tuhannya, lalu dia berhenti, maka apa yang telah diperolehnya dahulu menjadi miliknya dan urusannya (terserah) kepada Allah. Barangsiapa mengulangi, maka mereka itu penghuni neraka, mereka kekal di dalamnya.'

Sedangkan halal lawan kata batil, seperti yang sebutkan dalam Q.S. alBaqarah [2]: 188

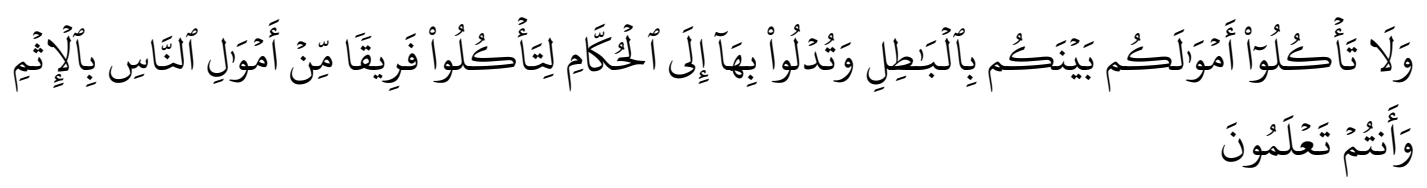

Terjemahannya:

'Dan janganlah kamu makan harta di antara kamu dengan jalan yang batil, dan (janganlah) kamu menyuap dengan harta itu kepada para hakim, dengan maksud agar kamu dapat memakan sebagian harta orang lain itu dengan jalan dosa, padahal kamu mengetahui.'

Dari dua ayat diatas dapat diketahui bahwa makanan halal yang pada dasarnya halal secara dzatiyah hukumnya bias berubah menjadi haram apabila diperoleh dengan cara yang dilarang Allah, seperti hasil riba, harta anak yatim yang diambil secara paksa, mencuri, merampas, suap, menipu, judi dan lain-lain.

2) Makanan halal secara dzatiyah (subtansi barangnya)

Menurut syeh Sayyid Sabiq, secara subtansi makanan terbagi menjadi dua yaitu,jamad (benda mati) dan hayawan (binatang).

a) Jamad, yaitu semua jenis makanan yang berupa benda mati adalah halal, asalkan tidak najis, busuk, berbahaya dan memabukkan.

b) Binatang, hukum tentang konsumsi hewan halal dapat dibagi menjadi dua kategori, yaitu binatang darat dan binatang laut. Hukum binatang 
darat, sebagian ada yang halal dan ada pula yang haram. Halalnya bainatang yang hidup di darat ter kenal dengan "bahimatul an'am". Sebagaimana dijelaskan dalan Q.S. al-Maidah [5] : 1

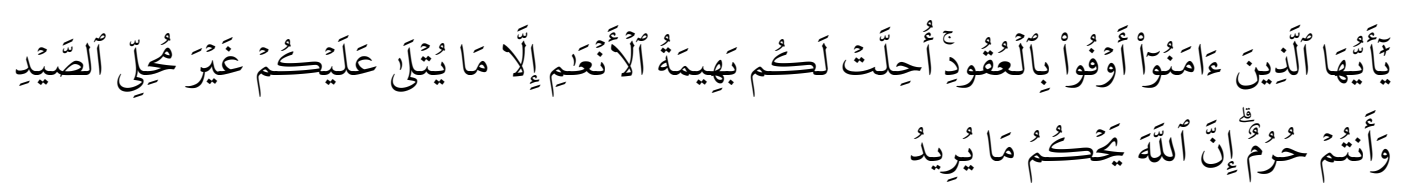

Terjemahannya:

'Wahai orang-orang yang beriman! Penuhilah janji-janji. Hewan ternak dihalalkan bagimu, kecuali yang akan disebutkan kepadamu, dengan tidak menghalalkan berburu ketika kamu sedang berihram (haji atau umrah). Sesungguhnya Allah menetapkan hukum sesuai dengan yang Dia kehendaki.'

b. Kriteria Makanan dan Minuman yang Haram

Ada dua standar untuk menjadikan makanan tersebut haram, yaitu makanan haram secara dzatiyah, maksud dari haram secara dzatiyah adalah makanan tersebut diharamkan karena zat yang terkandung dalam makanan tersebut, dan makanan haram ghair dzatiyah, maksud dari haram gahir dzatiyah adalah melihat dari sisi bagaimana mendapatkan makanan tersebut

1) Makanan yang Hukumnya Haram secara Dzatiyah

Makanan yang hukumnya haram secara dzatiyah adalah makanan yang hukumnya haram dikarenakan secara zatnya atau substansinya diharamkan. Jenis kenis makanan yang diharamkan hukumnya secara Dzatiyah, diantaranya adalah:

a) Beberapa contoh makanan yang keharamannya disebutkan di dalam al-Qur`an, yaitu:

(1) Bangkai hewan, al Qur'an membahas keharaman bangkai dalam suarat al Baqarah ayat 173, surat al-Maidah ayat 3, dan surat al-An'am ayat 145

(2) Darah, al Qur'an membahas keharaman darah dalam beberapa surat yaitu: surat al-Baqarah ayat 173, Surat al-An'am ayat 145 dan surat al-Maidah ayat 3

"yang dimaksud "bahimatul an'am" adalah unta sapi kerbau dan kambing 
(3) Daging Babi, al-Qur'an membahas keharaman daging babi dalam beberapa surat, yaitu: surat al-An'am ayat 145, surat al-Baqarah ayat 173 dan surat alMaidah ayat 3

(4) Daging binatang yang disembelih dengan menggunakan nama selain nama Allah, al-Qur'an membahas keharaman daging hewan yang tidak disembelih dengan nama selain Allah dalam beberapa surat, yaitu: surat al-An'am ayat 145, surat al-Maidah ayat 3 dan surat al-Baqarah ayat 173

(5) Daging binatang yang tidak disebut asma Allah ketika disembelih, al-Qur'an membahas keharaman hukum tersebut dalam surat al-An'am ayat 118 dan 121

(6) Minuman keras (Khamr) Hal ini disebutkan dalam surat Al-Baqarah ayat 219, Al-Maidah ayat 90-91. Contoh mengenai masalah minum bir yang banyak dikonsumsi oleh masyarakat. Telah diketahui bahwa sebagian orang yang ahli dalam penelitian menetapkan bahwa bir terdapat kandungan alkohol 3 - 5 \%. Karena alkohol adalah sesuatu yang dapat memabukkan maka bir diharamkan. Sehubungan dengan minuman keras (khamar), Rasulullah banyak memberi pertanyaan kepada kaum muslimin agar tidak menkonsumsi barang syaithan itu. Ditegaskan dalam sabda nabi: “Tiap-tiap yang memabukkan adalah haram".(HR. Muslim). Dan sabdanya lagi : "Sesuatu yang memabukkan, banyak ataupun sedikit adalah haram".(HR. An-Nasai dan Abu Daud). ${ }^{6}$

b) Makanan yang keharaman hukumnya disebutkan dalam dalam Hadith Nabi, antara lain:

(1) Makanan atau minuman yang kotor dan menjijikan. Contoh makanan atau minuman yang kotor dan menjijika misalnya : Ulat, cacing, kecoa, tikus, belatung, bekicot dan lainnya maka tidak boleh dikonsumsi.

(2) Daging dari hewan binatang buas, maksud dari binatang buas itu sendiri adalah hewan yang berkuku tajam dan bertaring. Hal ini dijelaskan dalam

${ }^{5}$ Hasan Murad, Masalah-Masalah Aktual Jawaban Islam Atas Problematika Kontemporer (Surabaya: al-Miftah, 2001), 156.

${ }^{6}$ Mohammad Fachrurrozy, Mutiara Qolbu, Jilid II (Jakarta: Pustaka al-Husna Baru, 2006), 76. 
Hadith riwayat Imam Bukhori dan Imam Muslim bahwasanya Rasulullah saw melarang untuk memakan seluruh hewan buas yang bertaring dan burung yang berkuku mencengkram. Misalnya: Beruang, Kucing, Harimau, Singa, Anjing, Ular dan lain-lain.?

Melihat dari segi asal dzatiyahnya, seluruh makanan diambil dari dua sumber yaitu: nabati (produk tumbuhan) dan hewani (produk hewan). Seluruh minuman pada umunya duhukumi halal jika minuman tidak beracun atau tidak berniat digunakan dalam membuat makanan yang haram, seperti menanam anggur untuk membuat wine atau bir. Diperbolehkannya untuk memakan tumbuh-tumbuhan dan buah-buahan dijelaskan dalam Q.S. Al An'am [6] : 141

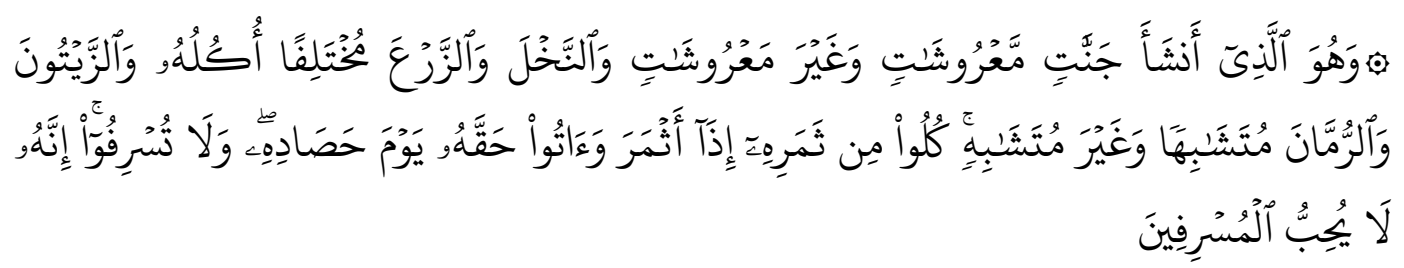

Terjemahannya:

'Dan Dialah (Allah) yang menjadikan (untuk kamu) kebun-kebun yang menjalar tanamannya dan yang tidak menjalar, pohon-pohon tamar dan tanaman yang berlainan (bentuk, rupa dan rasa) buahnya, zaitun, delima yang bersama [warna dan daun dan tidak bersama (rasa)]. Makanlah buahnya ketika ia berbuah dan keluarlah haknya pada hari memetiknya (menuai).

Produk yang sumber asalnya dari hewan atau biasa kita sebut produk hewani, dalam hukum Islam sudah dijelaskan dengan sangat jelas. Hewan yang dihukumi halal untuk dimakan harus mengikuti prosedur yang sudah diatur dalam Fikih salah satunya yaitu disembelih yang sesuai dengan ajaran Islam. Memotong hewan yang disahkan menurut hukum Islam adalah memotong dua saluran utama leher hewan, yaitu saluran pernafasan dan makanan. Menyembelih hewan yang sempurna adalah dengan terpotongnya juga dua urat nadi leher. Tujuan dari menyembelih hewan secara hukum Islam di samping untuk mematikan hewan dengan tidak terlalu lama menyakiti hewan tersebut juga untuk menghilangkan darah dari daging. dikarenakan darah haram dikonsumsi.

${ }^{7}$ Muhammad Khalis Mu'tashim, Laa Tansa Ya... Muslimin (Jakarta: Alifbata, 2007), 341. 
2) Makanan yang haram secara Ghair Dzatiyah

Makanan yang dihukumi haram secara Ghair Dzatiyah adalah makanan yang dilihat dari cara mendapatkannya makanan tersebut hukumnya haram. Adapun jenis makanan yang hukumnya haram secara Gahair Dzatiyah, antara lain:

a) Harta atau Makanan hasil dari mencuri

Mencuri yang dimaksud yaitu mengambil, menggunakan atau memanfaatkan barang tersebut tanpa izin dari pemilik yang sah secara hukum. Diantara hal tersebut, antara lain

(1) Makanan yang hukumnya halal secara dzatiyahnya, tetapi makanan tersebut hasil dari mencuri.

(2) Mencicipi makanan atau buah tanpa meminta ijin penjualnya saat berada di warung atau kios.

b) Harta atau Makanan hasil berjudi

Harta atau Makanan yang didapatkan dari hasil judi merupakan sesuatu yang didapatkan dengan membeli impian akan mendapatkan sesuatu yang luar biasa dengan pengorbanan yang kecil. Beberapa kategori yang termasuk dalam makna judi adalah:

(1) Berjudi dengan mengirim pesan singkat/SMS

(2) Berjudi dengan media Toto Gelap, kartu, totor dan yang lainnya

(3) Berjudi melalui sepeda gembira.

(4) berjudi dengan mengikuti sayembara, kuis, kupon berhadiah, dan yang lainnya.

c) Harta atau Makanan hasil dari riba

Harta atau makanan yang diperoleh dari riba atau segala bentuk jual beli yang mengandung unsur gharar atau tidak jelas, akan menimbulkan kekecewaaan dan menimbulkan konflik dikemudian hari, hukumnya adalah haram. Beberapa contoh yang sering terjadi dalam keseharian adalah:

(1) Mengambil manfaat bunga bank; 
(2) Jual beli suatu barang yang belum jelas wujud dan keberadaannya, seperti Jual beli ketela, Namun kete tersebut masih berada dalam tanah, atau jual beli hewan yang masih berada dalam kandungan;

(3) Jual beli sistem ijon yaitu membeli padi yang belum siap dipanen (belum masak) dan padi tersebut diambil ketika padi tersebut sudah siap dipanen (sudah masak).

d) Harta atau makanan hasil dari korupsi

Dalam hal ini yang termasuk didalamnya adalah segala harta atau makanan yang didapatkan dengan cara mengambil hak masyarakat untuk kepentingan pribadi dengan cara menyalahgunakan wewenangnya.

e) Harta atau makanan hasil dari jual beli barang yang hukumnya haram

Diriwayatkan dari Anas bin Malik bahwa Rasulullah Saw. Bersabda:

"ada sepuluh orang yang terkutuk karena terlibat dalam masalah khamar, yaitu: orang yang membuat, orang yang mengedarkan, orang yang meminum, orang yang membawa, orang yang mengirim, orang yang menuang, orang yang menjual, orang yang memanfaatkan hasil penjualannya, orang yang membayar, dan orang yang memesan"(HR. Ibnu Majah dan Tirmidzi).

(1) Uang yang diperoleh dari hasil melakukan jual beli khamr (minuman keras), Narkoba, dan yang lainnya.

(2) Uang yang diperoleh dari hasil melakukan jual beli daging bangkai, babi dan yang lainnya

f) Harta atau Makanan hasil dari suap menyuap

Menyuap adalah memberikan sesuatu yang dalam hal ini baik berupa uang atau berupa benda kepada penguasa agar urusan dumudahkan dan dipercepat. Hal seperti ini sering terjadi didalam orang orang terjerat permasalahan hukum, contohnya pejabat yang seharusnya divonis bersalah menjadi tidak bersalah karena menyuap, atau beberapa profesi yang lainnya. Dalam masalah suap menyuap, Rasulullah menyampaikan bahwa Orang yang menyuap dan orang yang disuap, duaduanya dilaknat oleh Allah.

\footnotetext{
${ }^{8}$ Sudiro Masruhi, Islam Melawan Narkoba (Yogyakarta: Madani Pustaka Hikmah, 2000), 96.
} 


\section{Sertifikasi Makanan Halal}

Sertifikat halal merupakan bukti yang berupak dokumen dimana dalam dokumen tersebut menyatakan kehalalan suatu produk yang telah menjalani beberapa proses pemeriksaan kehalalan yang dilaksanakn oleh lembaga berwenang. Label halal adalah label yang diberikan pada kemasan pangan yang menginformasikan kepada konsumen bahwa produk tersebut telah menjalani proses pemeriksaan kehalalan dan telah dinyatakan halal, dalam hal ini telah memiliki sertifikat halal.

Masalah "halal" di Indonesia mendapat perhatian yang cukup besar. Terlebih setelah adanya kasus babi pada tahun 1989 pihak MUI membentuk suatu badan yang secara khusus menangani masalah perlindungan konsumen. Yaitu dengan membentuk Lembaga Pengkajian Pangan, Obat-Obatan Dan Kosmetik (LP-POM) pada tanggal 6 Januari 1989. Dengan adanya lembaga ini bersama komisi fatwa, memungkinkan MUI menjadi pioner dalam menggeluarkan sertifikasi halal dengan visi agar semua makanan temasuk obat-obatan dan kosmetika di Indonesia berlabel halal.

Dalam pemeriksaan halal dan dalam labelisasai halal dilakukan secara bersama-sama oleh LPPOM-MUI, BPOM (Badan Pengawas Obat dan Makanan) dan Kementrian Agama. dikecualikan bagi produsen yang hanya ingin mendapatkan sertifikat halal pada produduk meraka, maka proses pemeriksaan hanya melibatkan auditor dari LPPOM-MUI. Tugas dari masing-masing auditor adalah sebagai berikut:

a. Auditor dari LPPOM-MUI bertugas menangani suatu masalah yang berkaitan dengan aspek kehalalan produk tersebut. Dalam hal ini pemeriksaan dilakukan dengan meliputi beberapa hal seperti sumber bahan baku, bahan pembantu dan bahan tambahan. Selain itu juga diperiksa proses produksi dan sistem jaminan halal (halal insurance system).

b. Auditor BPOM bertugas menangani masalah yang berkaitan dengan kebersihan/hygienes, sanitasi dan Hazard Critical Control Point (HACCP) yang dilakukan selama proses produksi 
c. Auditor dari Kementerian Agama bertugas dengan cara memberikan pendapat dan masukan dari aspek Fikih, hukum dan spriritual kepada produsen dan internal auditor halal.

Kemudian pada permasalahan labelisasi, yaitu suatu produk aman untuk dikonsunsi. Merupakan suatu kewajiban bagi produsen mencantumkan dalam produk tentang spesifikasi barang.

Ada tiga macam bentuk labeling, yaitu:

a. Grade Labeling, ialah mencantumkan informasi ciri barang secara ringkas

b. Deskreptive Labeling, ialah memberikan unsur-unsur kimia yang digunakan untuk membuat makanan, bahan-bahan yang digunakan, serta kadaluwarsa barang

c. Invormative Labeling, ini sama dengan descirtif labeling,hanya saja lebih rinci. Seperti kita lihat keternagan dalam kemasan obat yag menerangaan tentang bahan-bahan yang digunakan, cara pemakaian obat, manfaat serta indikasi apabila konsumen mengalami kontradiksi.

Terkait masalah pemeriksaan produk pangan yang dapat dilabelisasi halal, dari pihak para ahli (LP POM MUI) mempunyai beberapa kriteria, yaitu dinilai dari bahan baku yang dipakai,bahan tambahan, proses menjalankan produksi, dan jenis kemasannya. Dalam proses menelusuri bahan bahan tersebut tidak hanya sekedar dari babi atau bukan, tetapi juga meliputi cara penyembelihan, penyimpanan, dan metode produksi.

LP POM MUI, dalam melakukan pemeriksaan menggunakan uji labortorium sebagai titik uji klinis. Kemudian titik kritis yang biasa terdapat dalam makanan olahan adalah babi dan turunannya. Namun ternyata dengan uji klinis labolatorium secanggihpun tak semua komponen-kemponen tersebut dapat terdeteksi. Contoh paling mudah adalah masalah penyembelihan. Sampai saat ini belum detemukan alat yang dapat mendeteksi apakah daging itu dari hewan yang disembelih dengn membaca"basmallah" atau tidak. Atau penyembelihnya orang islam atau tidak. Untuk permaslahan seperti ini, untuk pemeriksaannya harus dilihat secara langsung dari proses sebeslumnya, yaitu cara penyambelihan yang diajarkan syari'at islam. 
Secara legalitas perundangan, perlindungan konsumen belum diatur secara khusus, tetapi hak konsumen Indonesia telah berhasil dirumuskan pada tanggal 15 Mei 1962, yan gdiperkenalkan degan nama Panca Hak Konsumen yang terdiri dari :

a. Hak atas keamanan dan keselamatan

b. Hak atas informasi

c. Hak atas memilih

d. Hak atas didengar

e. Hak mendapatkan llingkungan yang bersih

Dari keterangan di atas maka konsumen menduduki menduduki peringkat pertama. Para konsumen harus terlidungi bahan pangannya dari pencemaran bahan-bahan haram, baika bahan utama maupun bahan auiditif dalam proses pengolahannya.

\section{Problematika Masyarakat}

Sertifikasi halal didalam lingkup masyarakat modern seperti sekarang ini menimbulkan sedikit kerisauan terhadap beberapa produk yang tidak memiliki sertifikat halal. Apabila ditinjau dalam kitab - kitab fiqih, kita akan menemukan altahrîm wal ihlâl haqqulLâh wahdah. Artinya, mengharamkan dan menghalalkan suatu barang atau benda tertentu adalah murni hak preogratif dari Allah. Dari sinilah tidak ada seorangpun yang berhak menyatakan ini halal atau itu haram kecuali atas apa yang telah ditetapkan oleh Tuhan langsung melalui nashNya.

Namun menjadi catatan, bahwa yang hukumnya diharamkan oleh Allah itu jauh lebih sedikit jika dibandingkan dengan yang hukumnya boleh atau halal. Maksudnya adalah seuatu yang hukumnya boleh atau halal lebih banyak dari pada yang hukumnya diharamkan. Tercatat didalam Alqur'an hanya ada beberapa suatu barang atau benda yang hukumnya haram. Jika dilihat dari ayat al-Qur'an, benda yang haram karena zatnya yaitu hanya babi. Walaupun ada beberapa makanan yang hukumnya haram, seperti al-mauqûdah dan al-mutaraddiyah, tapi itu (diharamkan) bukan karena dzatiyahnya. Jadi, yang termasuk dalam wilayah yang hukumnya haram itu sangat sempit dalam ajaran hukum Islam. 
Sebagian ulama berpendapat bahwa makanan yang halal dan baik bukan makanan yang dilabelisasi halal oleh orang-orang tertentu yang telah dijelaskan diatas. Makanan halal dan baik yaitu yang dianggap baik oleh naluri kemanusiaan yang normal pada umumnya, atau dianggap baik oleh seluruh manusia. Jadi bukan makanan yang dianggap baik oleh orang-orang tertentu saja. Makanan yang buruk adalah sebaliknya.

Label halal dalam hal ini berhubungan dengan kehalalan dan keharaman sesuatu yang diserahkan hanya kepada lembaga tertentu yaitu LPPOM-MUI, BPOM (Badan Pengawas Obat dan Makanan) dan Kementrian Agama. Akan tetapi jika dilihat dari kondisi masyarakat akan berbeda dengan kondisi masyarakat lainnya. Begitu pula komunitas tertentu akan berbeda dengan komunitas yang lainnya. Keputusan menegnai permasalahan sesuatu itu dihukumi halal atau haram, dianggap menjijikan atau tidak, sebenarnya akan lebih banyak dinilai atau ditentukan oleh masyarakat. Bisa jadi sejenis makanan atau hewan tertentu dipandang tidak baik oleh suatu kelompok tertentu, tapi baik menurut kelompok yang lainnya. Bagi orang yang menganggap makanan tertentu jelek atau khabâ’its, haram bagi dia memakannya.

Bagi kelompok tertentu yang menyatakan bahwaa barang yang sama adalah baik, maka mereka boleh memakan barang itu. Seperti contoh, bagi orang yang tinggal di daerah pegunungan, memakan katak merupakan hal wajar dan sesuai dengan karakteristik mereka. Jadi, menurut mereka itu tidak menjadi masalah. Tetapi menurut pendapat kelompok lain, katak itu makanan yang menjijikkan dan hukumnya haram.

Persoalan ini menjadi sangat mudah sekali. Apa standar penilaian halal dan haram itu? Sesuatu yang bermanfaat dan berguna bagi badan, itu dihukumi halal; sesuatu yang tidak bermanfaat dan tidak berguna bagi badan dan juga berdampak buruk baik secara fisik atau pun psikis, maka ia dihukumi haram. Bahkan dalam pembahasan Fikih klasik dijelaskam bahwa seandainya ular itu tidak mengandung racun atau bisa, maka ular tersebut boleh saja dimakan. Bahkan meminum racun sekalipun, jika tidak berbahya bagi fisik tubuh seseorang, maka tidak apa-apa. Artinya, tanpa diatur-atur sekalipun, orang yang normal bisa menalar sendiri 
kepentingannya dalam soal makanan. Namun sekiranya labelisasi itu diperlukan demi keamanan, maka kami setuju dengan adanya "labelisasi haram" karena makanan yang haram memiliki wilayah yang sempit dan memang pada dasarnya segala sesuatu itu boleh (al-ashl fil asyấ al-ibahah) kecuali kalau ada dalil agama yang mengharamkan (hattâ yadullad dalîl 'alâ tahrîmih) sehingga tidak diperlukan labelisasi halal.

\section{KESIMPULAN}

Dapat ditaraik kesimpulan dari pembahasan diatas bahwa Pada dasarnya segala sesuatu yang diciptakan Allah di muka bumi ini hukumnya mubah, tidak ada satupun yang hukumnya haram kecuali adanya nas yang sah dan tegas yang mengharamkannya.

Kriteria makanan yang halal dan haram ditinjau dari dua aspek yaitu dzatiyah (substansi zat) dan ghair dzatiyah (cara memperolehnya). Makanan yang baik atau halal adalah makanan yang dianggap baik oleh naluri kemanusiaan pada umumnya yang normal, atau dianggap baik oleh semua manusia dan begitu juga dengan makanan yang buruk. Ada tiga problematika terkiat permasalahan labelisasi halal yang selama ini haknya ada di tangan Majelis Ulama Indonesi (MUI), Pertama adalah permasalahan politis yang ditimbulkan dari persoalan labelisasi itu sendiri; Kedua adalah masalah keagamaan; dan Ketiga adalah terkait masalah ekonomi.

Labelisasi halal tidaklah diperlukan karena naluri manusia sendiri bisa membedakan suatu hal yang memberi manfaat dan mafsadat bagi dirinya sendiri. Akan tetapi jika sekiranya diperlukan, maka bukan kehalalan yang dilabelisasi melainkan keharaman (labelisasi haram) dengan meninjau wilayah hukum yang lebih sempit dan tiga aspek diatas.

\section{REFERENSI}

Al-Banjari, M. A. (2002). Kitab Sabilal Muhtadin. In Juz II. Surabaya: Bina Ilmu. Fachrurrozy, M. (2006). Mutiara Qolbu (Jilid II). Jakarta: Pustaka al-Husna Baru. Muhammad Khalis Mu'tashim. (2007). Laa Tansa Ya... Muslimin. Jakarta: Alifbata. Murad, H. (2001). Masalah-Masalah Aktual Jawaban Islam atas Problematika Kontemporer. 
Surabaya: al-Miftah.

Qardhawi, Y. (2007). Halal Haram dalam Islam (W. Ahmadi, M. Badawi, \& Saptorini, trans.). Solo: Era Intermedia.

Sudiro Masruhi. (2000). Islam Melawan Narkoba. Yogyakarta: Madani Pustaka Hikmah. www.nuramaya's.blogspot.com

www.wikipedia.com

www.islamlib.com

http://lppommuikaltim.multiply.com/feed.rss 